University of Nebraska - Lincoln

DigitalCommons@University of Nebraska - Lincoln

$5-16-2008$

\title{
Chemisorption of oxygen onto activated carbon can enhance the stability of biological perchlorate reduction in fixed bed biofilm reactors
}

Young Chul Choi

University of Illinois at Urbana-Champaign

Xu Li

University of Illinois at Urbana-Champaign

Lutgarde Raskin

University of Michigan - Ann Arbor

Eberhard Morgenroth

University of Illinois at Urbana-Champaign

Follow this and additional works at: https://digitalcommons.unl.edu/civilengfacpub

Part of the Civil Engineering Commons

Chul Choi, Young; Li, Xu; Raskin, Lutgarde; and Morgenroth, Eberhard, "Chemisorption of oxygen onto activated carbon can enhance the stability of biological perchlorate reduction in fixed bed biofilm reactors" (2008). Civil Engineering Faculty Publications. 27.

https://digitalcommons.unl.edu/civilengfacpub/27

This Article is brought to you for free and open access by the Civil Engineering at DigitalCommons@University of Nebraska - Lincoln. It has been accepted for inclusion in Civil Engineering Faculty Publications by an authorized administrator of DigitalCommons@University of Nebraska - Lincoln. 


\title{
Chemisorption of oxygen onto activated carbon can enhance the stability of biological perchlorate reduction in fixed bed biofilm reactors
}

\author{
Young Chul Choi, ${ }^{1,2}{ }^{\mathrm{Xu} \mathrm{Li}}{ }^{3}$ Lutgarde Raskin, ${ }^{3}$ and Eberhard Morgenroth ${ }^{1,4}$
}

\author{
${ }^{1}$ Department of Civil and Environmental Engineering, University of Illinois at Urbana-Champaign, Urbana, IL 61801, USA \\ ${ }^{2}$ Current address - Doosan Hydro Technology Inc., Tampa, FL, USA \\ ${ }^{3}$ Department of Civil and Environmental Engineering, University of Michigan, Ann Arbor, MI 48109, USA \\ ${ }^{4}$ Department of Animal Sciences, University of Illinois at Urbana-Champaign, Urbana, IL 61801, USA
}

Corresponding author - E. Morgenroth, Department of Civil and Environmental Engineering, University of Illinois at UrbanaChampaign, 3219 Newmark Civil Engineering Laboratory, MC-250, 205 North Mathews Avenue, Urbana, IL 61801, USA;

tel 217 333-6965, fax 217 333-6968, email emorgenr@uiuc.edu

\begin{abstract}
Fixed bed biofilm reactors with granular activated carbon (GAC) or glass beads as support media were used to evaluate the influence of short-term (12 h) and long-term (23 days) increases of influent dissolved oxygen (DO) concentrations on biological perchlorate removal. The goal was to evaluate the extent by which chemisorption of oxygen to GAC can enhance the stability of biological perchlorate reduction. Baseline influent concentrations were $50 \mu \mathrm{g} / \mathrm{L}$ of perchlorate, $2 \mathrm{mg} / \mathrm{L}$ of acetate as C, and $1 \mathrm{mg} / \mathrm{L}$ of DO. Perchlorate removal in the glass bead reactor seized immediately after increasing influent DO concentrations from 1 to $4 \mathrm{mg} / \mathrm{L}$ since glass beads have no sorptive capacity. In the biologically active carbon (BAC) reactor, chemisorption of oxygen to GAC removed a substantial fraction of the influent DO, and perchlorate removal was maintained during short-term increases of influent DO levels up to $8 \mathrm{mg} /$ L. During long-term exposure to influent DO concentrations of $8.5 \mathrm{mg} / \mathrm{L}$, effluent perchlorate and DO concentrations increased slowly. Subsequent exposure of the BAC reactor bed to low DO concentrations partially regenerated the capacity for oxygen chemisorption. Microbial analyses indicated similar microbial communities in both reactors, which confirmed that the differences in reactor performance during dynamic loading conditions could be attributed to the sorptive properties of GAC. Using a sorptive biofilm support medium can enhance biological perchlorate removal under dynamic loading conditions.
\end{abstract}

Keywords: granular activated carbon, biologically active carbon, chemisorption, oxygen, perchlorate, biofilm, clone library

\section{Introduction}

Perchlorate $\left(\mathrm{ClO}_{4}^{-}\right)$is an oxidizing anion, which is commonly used in the form of ammonium perchlorate in rocket fuels, air bags, road flares, and other industrial applications (Urbansky, 1998). Since the introduction of an analytical method that can measure perchlorate accurately at $\mu \mathrm{g} / \mathrm{L}$ levels (USEPA, 1997), perchlorate has been reported to be present in many drinking water sources (Gullick et al., 2001). Removal of perchlorate from drinking water sources can be achieved using abiotic processes, such as ion exchange (Roquebert et al., 2000; Urbansky, 1998), reverse osmosis (Urbansky, 1998), electrodialysis (Roquebert et al., 2000), and tailored activated carbon (Chen et al., 
2005; Parette and Cannon, 2005), in addition to a range of biological processes. Biological reduction of perchlorate is carried out by perchlorate-reducing bacteria which can use perchlorate as an electron acceptor (Achenbach et al., 2001; Coates et al., 1999; Rikken et al., 1996). Compared to abiotic processes, biological processes can convert perchlorate to non-toxic chloride without generating waste streams that contain high concentrations of perchlorate or brines from regenerating ion exchange resins. Another advantage of biological treatment is that, in addition to perchlorate, other contaminants such as nitrate and bromate can be reduced in the same system (Nerenberg and Rittmann, 2004). While the reduction of these other contaminants is desirable, these oxidized compounds will compete with perchlorate for electron donors. In perchlorate-contaminated drinking water, the dominant competing electron acceptors are typically oxygen and nitrate. Microbial reduction of perchlorate is inhibited by high concentrations of oxygen and nitrate (Coates and Achenbach, 2004) and the application of biological processes for drinking water treatment may be problematic in case of variable influent oxygen or nitrate concentrations.

Biological removal of perchlorate has been evaluated in biofilm reactors using different carrier media including plastic (Min et al., 2004), sand (Min et al., 2004), Celite (Losi et al., 2002), and granular activated carbon (GAC) (Brown et al., 2002) for fixed bed reactors, and sand and GAC for fluidized bed reactors (McCarty and Meyer, 2005; Sutton, 2006). Other reactor configurations include membrane diffuser biofilm reactors (Nerenberg et al., 2002) and ion exchange membrane bioreactor (Matos et al., 2006). Advantages of using GAC as a carrier medium include the widespread application of GAC in drinking water treatment plants where existing GAC filters can easily be retrofitted to operate as biologically active carbon (BAC) reactors. In 2004, the California Department of Health Services issued a conditional approval of biological removal of perchlorate from drinking water sources using fixed bed BAC (CADHS, 2004).

Not only can GAC be used to support the growth of biofilms, but sorption by GAC has been shown to complement biological removal in BAC reactors under dynamic loading conditions (Hanaki et al., 1997; Herzberg et al., 2003; Jaar and Wilderer, 1992; Sutton, 2006). Based on mathematical modeling, Herzberg et al. (2003) showed that the sorptive capacity of GAC can be beneficial by serving as a temporary sink for contaminants and then allowing biological degradation of the sorbed contaminants. They demonstrated that sorption, intraparticle diffusion, and desorption resulted in increased biofilm activity on the GAC compared to non-absorbing carrier media. Kim and Logan (2000), however, pointed out a potential problem related to using GAC as a temporary sink. They observed increased effluent perchlorate concentrations after backwash and redistribution of the GAC within the reactor, and attributed increased effluent concentrations to the desorption of perchlorate from GAC. A better understanding of the interactions between sorption, desorption, biological processes, and reactor operation is needed to make use of the sorptive capacity to improve reactor performance (Sutton, 2006).
In addition to the direct benefits of acting as a temporary sink of target contaminants, the sorptive capacity of GAC should be able to enhance biological perchlorate removal indirectly by lowering the concentration of oxygen, the competing electron acceptor, through chemisorption. Molecular oxygen can be irreversibly removed by interacting with the GAC surface (Abuzaid and Nakhla, 1994; Prober et al., 1975): one oxygen molecule and two carbon atoms form two $\mathrm{C}-\mathrm{O}$ bonds (Zhu et al., 2000). Also, oxygen can be removed by reacting with surface $\mathrm{C}=\mathrm{O}$ groups to form carboxylic acid groups (Prober et al., 1975). Prober and coworkers showed that chemisorption of oxygen can sustain as much as 6000 bed volumes with 10-40 mg oxygen removed per $g$ of carbon. However, it is not clear to what extent this capacity can be regenerated through physical, chemical, or biological processes. The purpose of the current study was to examine how chemisorption of oxygen on GAC affects biological perchlorate reduction in a BAC filter. To study the specific effects of chemisorption, two identical laboratory-scale biofilm reactors were operated using GAC or glass beads as sorptive or non-sorptive carrier media, respectively. The effects of the sorption capacity of the GAC were evaluated by comparing oxygen and perchlorate removal during short- and long-term exposure to increased influent dissolved oxygen (DO) concentrations and during electron donor failure conditions.

\section{Materials and methods}

\subsection{Reactor setup and influent composition}

The two laboratory-scale fixed bed biofilm reactors had an inner diameter of $2.4 \mathrm{~cm}$ and a length of $14 \mathrm{~cm}$, which resulted in an empty bed volume of $63.4 \mathrm{~mL}$. One reactor was filled with GAC (Norit model RO 0.8, Amersfoort, The Netherlands); the other reactor was filled with glass beads (1-mm glass beads, etched using $0.25 \% \mathrm{HF}$ for $1 \mathrm{~h}$ to allow for a better adhesion of bacteria). Both reactors were operated in an upflow mode with completely mixed bulkphase conditions by adding a recirculation loop with a flow rate $\left(Q_{\text {recirculation }}\right)$ five times of the influent flow rate $\left(Q_{\text {influent }}=2.7 \mathrm{~mL} / \mathrm{min}\right)$. This corresponds to an empty bed contact time of $23.5 \mathrm{~min}$. The BAC reactor was seeded using biomass collected from two other BAC reactors: one had been fed Urbana (IL) tap water amended with acetate at a concentration of $2 \mathrm{mg} / \mathrm{L}$ as $\mathrm{C}$ and $50 \mu \mathrm{g} / \mathrm{L}$ perchlorate (Brown et al., 2002), the other had been fed Urbana groundwater amended with $50 \mu \mathrm{g} / \mathrm{L}$ perchlorate (Lin, 2004). Sorption capacities of the GAC for perchlorate and oxygen were exhausted before initial start-up by recirculating water containing $50 \mu \mathrm{g} / \mathrm{L}$ of perchlorate and saturated by oxygen through the reactor. The glass bead reactor was seeded using biomass from a previously operated 3-mm glass bead reactor, which had been seeded with biomass from the $B A C$ reactor used in the current study.

The synthetic influent was prepared with deionized water and contained $50 \mu \mathrm{g} / \mathrm{L}$ perchlorate, $0.15 \mathrm{mg} / \mathrm{L}$ of $\mathrm{NH}_{4} \mathrm{Cl}$ as $\mathrm{N}$, and $0.5 \mathrm{mM}$ phosphate buffer to maintain a $\mathrm{pH}$ of 7.5 . The influent DO level was adjusted to values between 1 and $8.5 \mathrm{mg} / \mathrm{L}$ by purging the influent with $\mathrm{N}_{2}$ gas. After purging, the influent was isolated from ambient air using a float- 
ing lid. Acetate, the sole electron donor, was provided with a syringe pump and mixed with the synthetic influent immediately before it entered the reactors. The final concentration of acetate entering the reactors was $2 \mathrm{mg} / \mathrm{L}$ as $\mathrm{C}$.

\subsection{Reactor operation}

Backwash was performed by pouring the content of each reactor into a $600 \mathrm{~mL}$ beaker, adding $125 \mathrm{~mL}$ of collected effluent, and stirring with a $7.5 \mathrm{~cm}$ long magnetic stir bar at 150 revolutions per minute (RPM) for $1 \mathrm{~min}$. After the supernatant was decanted, another $125 \mathrm{~mL}$ effluent was added to the beaker and the rest of the procedure was repeated. Then the reactor contents were poured back to the reactors. This type of backwash was defined as a "normal backwash." For a strong backwash, the contents of the reactors were stirred at 200 RPM for $1 \mathrm{~min}$, followed by decanting of the supernatant; this process was repeated four times.

Prior to this study, both the BAC and the glass bead reactors were operated with influent acetate and DO concentrations of $2 \mathrm{mg} / \mathrm{L}$ as $C$ and $1 \mathrm{mg} / \mathrm{L}$, respectively. Experiments were initiated (=day 0$)$ after both reactors had been consistently removing perchlorate to below $1 \mu \mathrm{g} / \mathrm{L}$ for at least 1 month. The influent DO level for the BAC reactor was increased from 1 to 4,6 , and $8 \mathrm{mg} / \mathrm{L}$ for 12-h periods on days 8,9 , and 14 , respectively. On day 15 , a normal backwash was conducted and then the influent DO level was increased again to $8 \mathrm{mg} / \mathrm{L}$ for a 12-h period. On day 17, a strong backwash was conducted. Finally, the influent DO level was increased again to $8 \mathrm{mg} / \mathrm{L}$ for $12 \mathrm{~h}$. The glass bead reactor also was exposed to transient DO increases from 1 to 4,6 , and $8 \mathrm{mg} / \mathrm{L}$ for 12 -h periods on days 256,279 , and 22, respectively. GAC and glass bead reactors were not operated side-by-side and the sequences of experiments in both reactors were different. However, the reactors were operated according to the stated baseline operating conditions and complete perchlorate removal was accomplished for at least 7 days prior to each experiment. Following a normal backwash of the glass bead reactor on day 25 , the influent DO concentration was increased again to $8 \mathrm{mg} / \mathrm{L}$ for $12 \mathrm{~h}$ on day 26 .

To study the responses of the BAC reactor to long-term exposures to high DO concentrations, the influent DO level was increased from 1 to $8.5 \mathrm{mg} / \mathrm{L}$ for 23 days starting on day 22. Then the influent DO level was decreased to $1 \mathrm{mg} /$ $\mathrm{L}$ on day 45 , and increased again to $8.5 \mathrm{mg} / \mathrm{L}$ on day 48 for 6 days. A normal backwash was performed on day 53 to test if detachment of biomass would influence the chemisorption capacity. To verify that perchlorate removal was the result of microbial activity, acetate addition was stopped for 4.5 days starting on day 60 for the BAC reactor and on day 364 for the glass bead reactor.

\subsection{Chemical analyses}

DO concentrations were measured using galvanic oxygen sensors (WTW CellOx 325 with Oxi 340i, Weilheim, Germany) and flow cells (WTW model D201, Weilheim, Germany) connected to reactor effluents. The detection limit for DO measurement was $0.01 \mathrm{mg} / \mathrm{L}$. Perchlorate was measured using an ion chromatograph (Dionex ICS-2000, Sunnyvale,
CA) with an AS50 autosampler and a conductivity detector. An AS16 column and an AG16 guard column were used and the detection limit was $1 \mu \mathrm{g} / \mathrm{L}$. The eluent was $65 \mathrm{mM}$ $\mathrm{KOH}$ at a flow rate of $1.2 \mathrm{~mL} / \mathrm{min}$ and the injection volume was $990 \mu \mathrm{L}$. Dissolved organic carbon (DOC) was measured using a UV-Persulfate TOC Analyzer (Tekmar-Dohrmann Phoenix 8000, Mason, $\mathrm{OH}$ ) with a detection limit of $0.2 \mathrm{mg} /$ $\mathrm{L}$ as C. Volatile suspended solids (VSS) were measured according to Standard Methods (APHA et al., 1998). The pressure drop across the BAC bed was measured using glycerinfilled pressure gauges (Lenz Inc., Dayton, $\mathrm{OH}$ ).

\subsection{Clone libraries and phylogenetic analysis}

Biomass samples were collected during backwashing from the $B A C$ reactor on days 17 and 53, and from the glass bead reactor on day 388. For both reactors, biomass was first sampled after the reactors had achieved complete perchlorate removal for at least 7 days. DNA was extracted from these samples using a Mo Bio Ultra Clean Soil DNA Extraction Kit (Mo Bio Laboratories, Carlsbad, CA), quantified using a NanoDrop 1000 (NanoDrop Technology, Wilmington, DE), and checked for DNA integrity by electrophoresis on a $1 \%$ agarose gel. Each DNA extract was PCR amplified in triplicate using bacterial primer 8F (5'AGAGTTTGATCCTGGCTCAG-3') and universal primer 1492R (5'-GG(C/T)TACCTTGTTACGACTT-3') (Richardson et al., 2002), which were synthesized by Invitrogen (Carlsbad, CA). The protocol of the PCR reaction was adopted from the work by Dojka et al. (1998). The reagents used in the PCR reaction were from Takara (Takara Inc., Japan). Pooled PCR products were loaded on an agarose gel and bands of the appropriate size were cut. Purified PCR products were extracted from the gel bands using MinElute Gel Extraction Kit (QIAGEN Inc, Valencia, CA), cloned into vectors, and transformed into competent Escherichia coli cells using TOPO TA Cloning Kit for Sequencing (Invitrogen, Carlsbad, CA). A total of 192 clones in glycerol stocks were submitted for each clone library for bi-directional sequencing (Genome Sequencing Center at Washington University, St. Louis, MO). Raw data from sequencing in both forward and backward direction were evaluated using the Ribosomal Database Project II (RDP) Pipeline to remove vector sequences (Cole et al., 2007). Either forward or backward sequences were used in this analysis, depending on which direction resulted in a higher number of sequences of good quality. The phylogenetic classification of the clones was conducted using the "Classification" function under "MyRDP" in RDP. Comparisons between two libraries were made using the "Library Compare" function in RDP.

\section{Results}

\subsection{Short-term increase of influent DO levels}

For the baseline condition with an influent DO concentration of $1 \mathrm{mg} / \mathrm{L}$ and an acetate concentration of $2 \mathrm{mg} / \mathrm{L}$ as $\mathrm{C}$, the BAC reactor reliably reduced perchlorate to below the detection limit of $1 \mu \mathrm{g} / \mathrm{L}$ for more than 1 month (data not shown) before the start of the experiment. When the in- 
fluent DO level was increased to 4,6 , and $8 \mathrm{mg} / \mathrm{L}$ for 12 $\mathrm{h}$ periods, effluent $\mathrm{DO}$ concentrations increased to $0.1,0.2$, and $0.4 \mathrm{mg} / \mathrm{L}$, respectively, and effluent perchlorate concentrations increased to $10-13 \mu \mathrm{g} / \mathrm{L}$ (Figure 1). Thus, even with increased influent $\mathrm{DO}$ concentrations, the $\mathrm{BAC}$ reactor was able to remove more than $90 \%$ of the influent DO and $75-80 \%$ of the influent perchlorate. When the influent DO level was lowered to $1 \mathrm{mg} / \mathrm{L}$ following each 12-h period, effluent DO concentrations rapidly decreased to nondetectable levels and perchlorate was removed to below detection limit within $2 \mathrm{~h}$.

Assuming a net yield of $0.4 \mathrm{~g} \mathrm{COD}_{\text {biomass }} / \mathrm{g} \mathrm{COD}_{\text {acetate }^{\prime}}$ an acetate concentration of $2 \mathrm{mg} / \mathrm{L}$ as $C$ can reduce $3.2 \mathrm{mg} / \mathrm{L}$ of DO. Thus, if chemisorption is not considered, for influent DO levels of 4, 6, and $8 \mathrm{mg} / \mathrm{L}$ the expected effluent (or bulk liquid) DO concentrations should be $0.8,2.8$, and $4.8 \mathrm{mg} / \mathrm{L}$, respectively. However, the observed effluent DO concentrations were much lower than these expected values. Control experiments using virgin GAC demonstrated that more than $4.7 \mathrm{mg}$ of $\mathrm{O}_{2}$ can be removed abiotically per gram of GAC through chemisorption (data not shown). Based on this capacity, chemisorption could in fact account for the observed increased removal of DO from bulk liquid.

For the glass bead reactor, similar short-term $(12 \mathrm{~h})$ increases in influent DO levels to 4,6 , and $8 \mathrm{mg} / \mathrm{L}$ resulted in effluent DO concentrations of approximately $0.8,2.6$, and $3.5 \mathrm{mg} / \mathrm{L}$, respectively (Figure 2). These observed effluent DO concentrations were much closer to the expected effluent $\mathrm{DO}$ values, assuming biological reduction as the only sink for oxygen. Furthermore, during these short-term increases in influent DO levels, perchlorate removal was compromised and the effluent perchlorate levels were close to the influent concentrations of $50 \mu \mathrm{g} / \mathrm{L}$.

Regular backwash is necessary in operating fixed bed biofilm reactors, as it can remove biomass in excess and to avoid clogging (Niquette et al., 1998). A normal backwash was conducted in the BAC reactor on Day 15 (Figure 1). The amount of biomass detached was $63.6 \mathrm{mg}$ VSS and the pressure drop across the bed decreased from $48 \mathrm{kPa}$ before to below the detection limit of $0.7 \mathrm{kPa}$ after backwash. Even though the amount of biomass was reduced during backwashing, no perchlorate was observed in the effluent of the BAC reactor after the backwash or even during the 12-h period when the influent DO level was raised again to $8 \mathrm{mg} /$ L. During the strong backwash on day 17, the amount of biomass removed was too low to be quantified using VSS measurements. Despite the additional removal of biomass, no perchlorate was observed in the effluent after the strong backwash and after the DO level was increased to $8 \mathrm{mg} / \mathrm{L}$ (Figure 1). Effluent DO concentrations were approximately

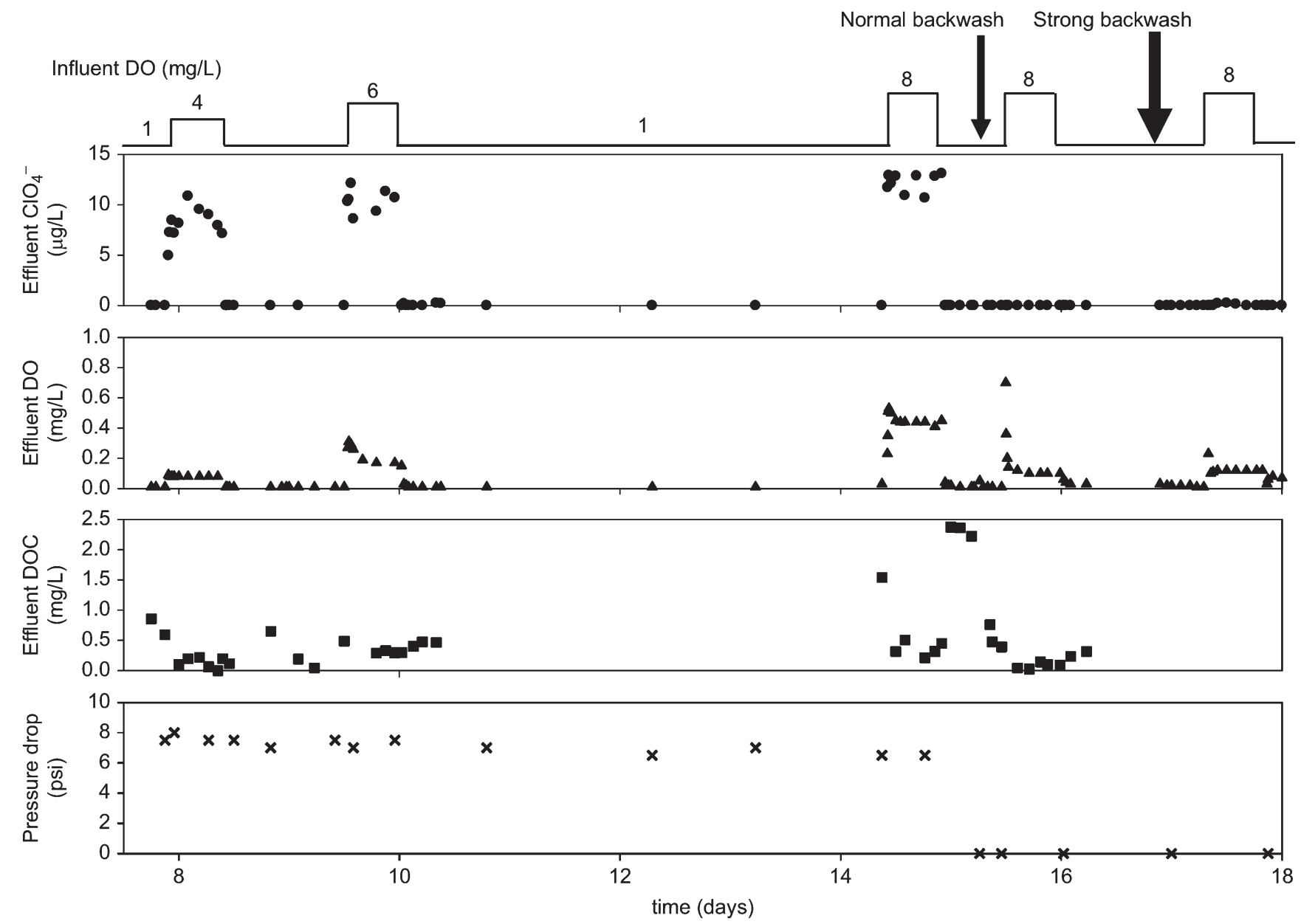

Figure 1. Effect of short-term (12 h) increases of influent DO levels to 4, 6, and $8 \mathrm{mg} / \mathrm{L}$ and backwashing on the performance of the BAC reactor. The influent acetate concentration was kept constant at $2 \mathrm{mg} / \mathrm{L}$ as $\mathrm{C}$. 


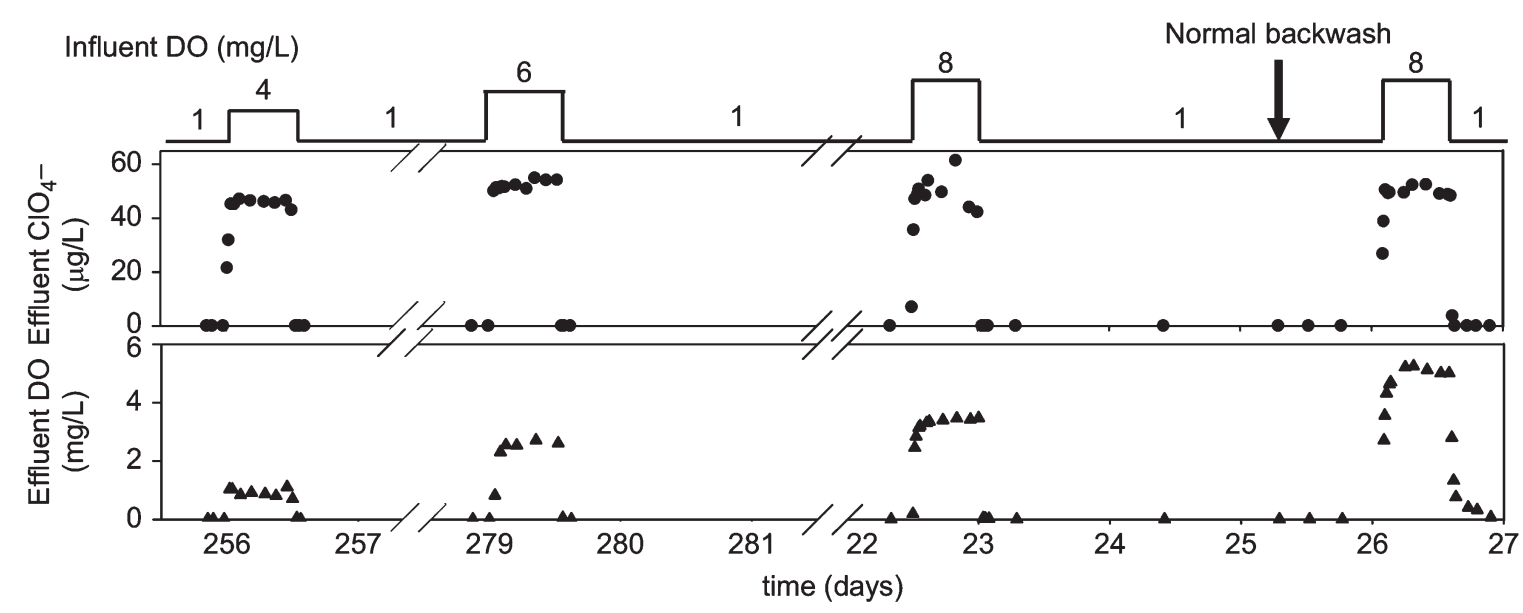

Figure 2. Effect of short-term $(12 \mathrm{~h})$ increases of influent DO levels to 4,6 , and $8 \mathrm{mg} / \mathrm{L}$ and backwashing on the performance of the glass bead reactor. The influent acetate concentration was kept constant at $2 \mathrm{mg} / \mathrm{L}$ as $\mathrm{C}$. Results are from three different experimental periods. Experiments were performed after steady-state removal of perchlorate had been achieved.

$0.12 \mathrm{mg} / \mathrm{L}$ during the last two $12-\mathrm{h}$ periods when the influent DO level was at $8 \mathrm{mg} / \mathrm{L}$. These effluent DO concentrations were much lower than those observed during the first 12-h period of $8 \mathrm{mg} / \mathrm{L}$ influent DO, but they were similar to those observed during the $12-\mathrm{h}$ period of $4 \mathrm{mg} / \mathrm{L}$ influent DO on day 8 (Figure 1) when incomplete perchlorate reduction was observed. The improved removal of both oxygen and perchlorate after backwashing indicates that perchlorate removal may have been accomplished through a combination of direct adsorption of perchlorate and biological perchlorate reduction under low bulk-phase DO levels that were the result of oxygen removal through chemisorption. Backwashing likely resulted in a decrease in biofilm coverage on GAC surface (patchy biofilms), and thus more GAC surface became available for sorption of oxygen and perchlorate, which resulted in improved perchlorate removal after backwashing (Herzberg et al., 2003).

Backwashing of the glass bead reactor resulted in increases of both perchlorate and oxygen concentrations in the effluent (Figure 2). During the 12-h increase in influent DO levels to $8 \mathrm{mg} / \mathrm{L}$ on day 22, the effluent DO concentration was approximately $3.5 \mathrm{mg} / \mathrm{L}$. During the 12-h increase in influent DO level to $8 \mathrm{mg} / \mathrm{L}$ on day 26, after the normal backwash on day 25, effluent DO concentrations were approximately $5 \mathrm{mg} / \mathrm{L}$, close to the expected value of $4.5 \mathrm{mg} /$ L. For the glass bead reactor, a larger amount of biomass in the reactor before backwashing resulted in greater DO removal (day 22) compared to the DO removal after backwashing (day 26), which is opposite to what was observed for the BAC reactor.

\subsection{Long-term increase of influent DO levels}

Long-term effects of increased influent DO levels were evaluated by operating the BAC reactor with an influent DO concentration of $8.5 \mathrm{mg} / \mathrm{L}$ for a period of 23 days (Figure 3). During this time, effluent perchlorate concentrations increased steadily and reached about $30 \mu \mathrm{g} / \mathrm{L}$. Effluent DO concentrations remained low $(<0.12 \mathrm{mg} / \mathrm{L})$ during the first 8 days of this period and began to increase after day 31. The increase in effluent DO concentrations corre- lated with a decrease in effluent DOC concentrations. The correlation can be explained by the depletion of GAC sorptive capacity, which resulted in an increased amount of DO in the bulk liquid that was available for biological oxidation of dissolved organics. The observed increase in effluent perchlorate concentrations over time did not appear to be affected by the changes in effluent DO and DOC levels. The pressure drop across the bed also gradually increased, from below the detection limit to $48 \mathrm{kPa}$ as a result of biofilm growth within the reactor.

When the influent DO level was decreased to $1 \mathrm{mg} / \mathrm{L}$ on day 46 (baseline conditions), the effluent perchlorate concentrations dropped immediately to $20 \mu \mathrm{g} / \mathrm{L}$ and then decreased slowly. It required 2.5 days to lower the effluent perchlorate concentration to below the detection limit. This is in contrast with the results obtained after the short-term exposure to increased influent DO level at $8 \mathrm{mg} / \mathrm{L}$ when perchlorate reduction was fully restored within $2 \mathrm{~h}$ (Figure 1).

As soon as complete perchlorate reduction was restored on day 48 , the influent DO level was increased again to $8.5 \mathrm{mg} / \mathrm{L}$ to test if the oxygen chemisorption capacity was restored during the 2.5 days of low $(1 \mathrm{mg} / \mathrm{L})$ influent DO levels (Figure 3 ). Unlike the gradual increase observed after the increase in the influent DO on day 23, the effluent perchlorate concentrations immediately increased to about $20 \mu \mathrm{g} / \mathrm{L}$ on day 48. This level is equal to the effluent perchlorate concentrations 13 days into the first long-term DO experiment, and perchlorate concentrations only slightly increased in the subsequent 5 days. The effluent DO concentrations increased within 2 days to $2.5 \mathrm{mg} / \mathrm{L}$, the same level that was only reached on day 46 , which corresponds to 23 days of the first period operating with high influent DO concentrations. These results demonstrate that the chemisorption capacity for both oxygen and perchlorate were depleted during the first 23 days of operation at high influent DO levels and that only part of the capacity was regenerated during the 2.5 days of operation at low DO conditions.

To examine the effects of backwashing on perchlorate removal after the chemisorption capacity of GAC was depleted, the BAC reactor was backwashed on day 53, while influent DO concentrations were maintained at $8.5 \mathrm{mg} / \mathrm{L}$ 


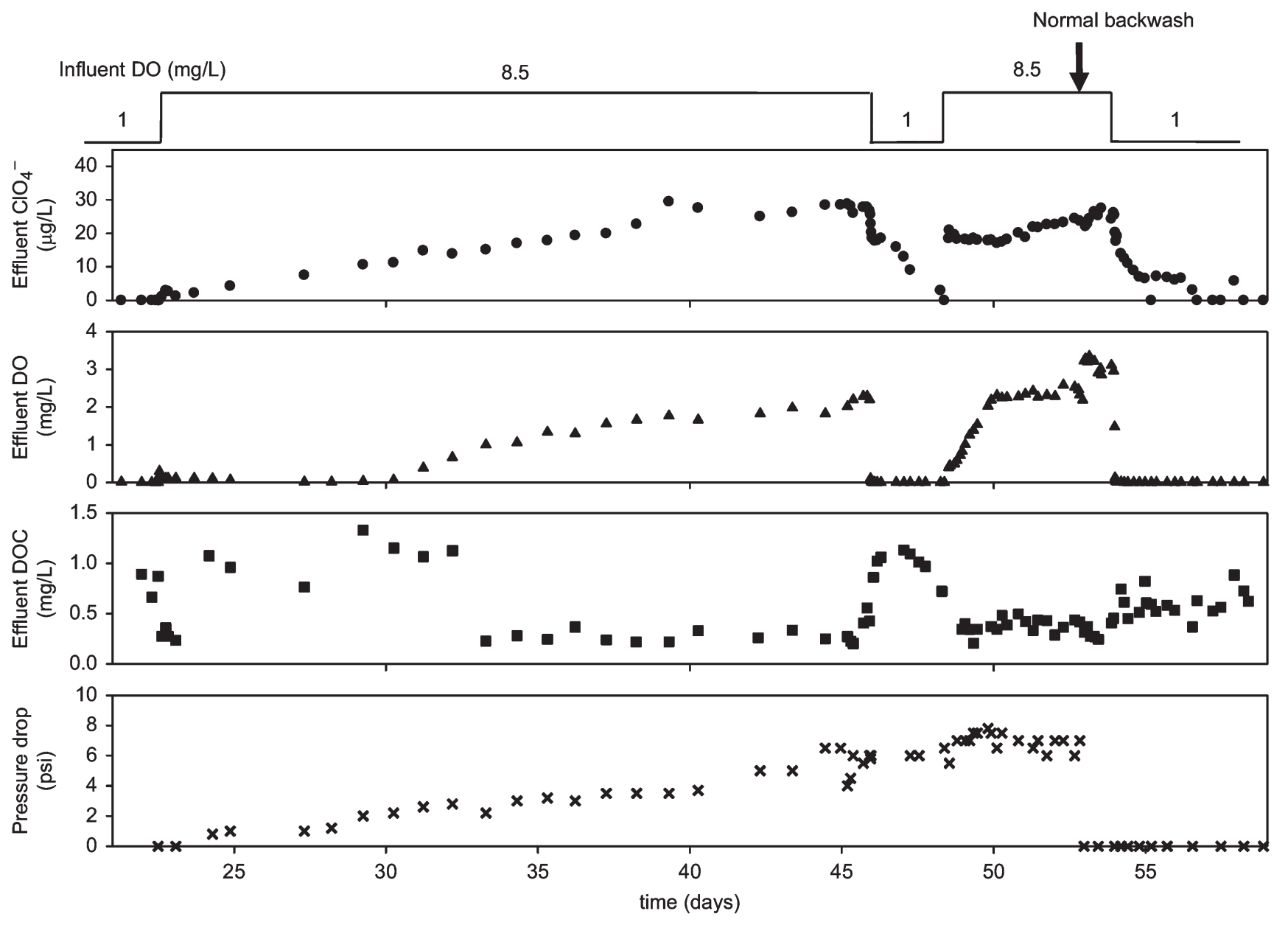

Figure 3. Response of the BAC reactor to long-term operation (duration of 23.4 and 5.6 days) with increased influent DO levels of $8.5 \mathrm{mg} /$ $\mathrm{L}$ and a backwash event. The influent acetate concentration was kept constant at $2 \mathrm{mg} / \mathrm{L}$ as $\mathrm{C}$.

(Figure 3). After backwashing, effluent DO and perchlorate concentrations remained high. This was different from the two backwash events in Figure 1, after which the BAC reactor was able to remove both $\mathrm{DO}$ and perchlorate to low levels under influent DO level at $8 \mathrm{mg} / \mathrm{L}$. This comparison suggests that once the sorptive capacity of GAC was depleted, the reactor lost the ability to lower $\mathrm{DO}$ and perchlorate levels when influent DO levels were high.

\subsection{Operation without electron donor addition}

Prior to evaluating operation without electron donor addition, the BAC and glass bead reactors were operated with an influent DO level of $1 \mathrm{mg} / \mathrm{L}$ and achieved complete perchlorate removal for 7 and 6 days, respectively (Figure 4). Eliminating acetate addition for a 4.5 -day period resulted in increases of effluent perchlorate concentrations in both reactors. However, the increase was much slower for the BAC reactor compared to the glass bead reactor. Near the end of the 4.5-day period, effluent perchlorate concentrations were about 30 and $45 \mu \mathrm{g} / \mathrm{L}$ in BAC and glass bead reactors, respectively. There was no increase in effluent DO concentrations for the BAC reactor (except for one outlier), while there was an immediate increase in the glass bead reactor and the effluent DO level reached $0.4 \mathrm{mg} / \mathrm{L}$ at the end of the experiment. Following electron donor addition, effluent perchlorate concentrations decreased rapidly in both reactors.

\subsection{Clone library results for the $B A C$ and glass bead reactors}

The composition of the microbial communities in the BAC and glass bead reactors was compared based on clone library results (Table 1). For the baseline operating conditions, the microbial communities contained large numbers of Betaproteobacteria $(62.2 \%$ and $64.3 \%$ of total identified clones in the BAC and the glass bead reactor, respectively). Dechloromonas was the only known genus of perchlorate-reducing bacteria found in the clone libraries, and accounted for $11.7 \%$ and $13.2 \%$ of the total clones in the BAC and the glass bead reactors, respectively. The genus Zoogloea, which also belongs to the Betaproteobacteria, was the most abundant bacterial genus in both reactors.

The structure of the bacterial community in the BAC reactor changed after the reactor had been exposed to increased influent DO concentrations for an extended period of time (day 53 in Figure 3). The abundance of the Betaproteobacteria decreased substantially. During the same time period, the numbers of clones that were associated with the 


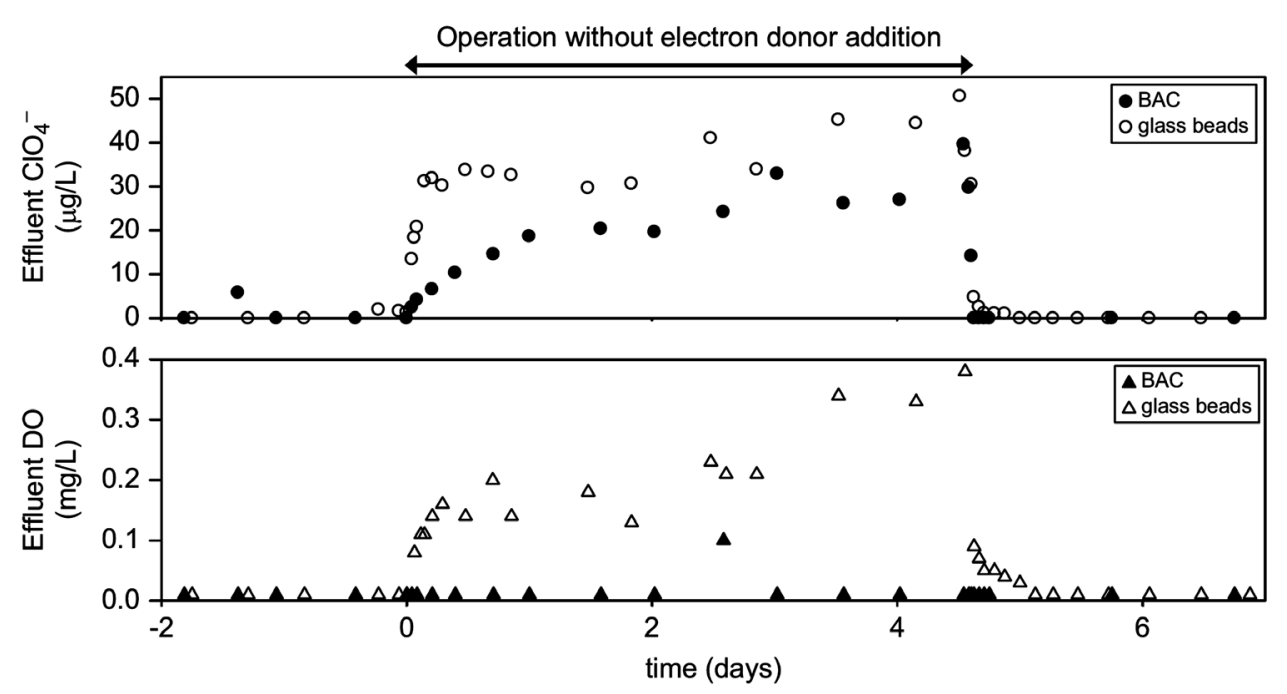

Figure 4. Effluent perchlorate and DO concentrations for the BAC and glass bead reactors in response to operation without electron donor addition, while maintaining the influent DO level at $1 \mathrm{mg} / \mathrm{L}$. Day 0 corresponds to day 60 and day 364 for the BAC and glass bead reactors, respectively.

Table 1. Dominant bacterial populations (in \% of total clones) in biomass samples collected from backwash water of the BAC and glass bead reactors

\begin{tabular}{lcrc}
\hline Source of biomass & \multicolumn{2}{c}{ BAC reactor } & Glass bead reactor \\
\cline { 2 - 4 } Sampling dates & Day 17 & Day 53 & Day 388 \\
Number of clones sequenced & $n=180$ & $n=179$ & $n=182$ \\
\hline Betaproteobacteria $^{\text {a }}$ & 62.2 & 34.1 & 64.3 \\
$\quad$ Dechloromonas & 11.7 & 1.7 & 13.2 \\
Zoogloea & 30.6 & 10.1 & 25.8 \\
Other Betaproteobacteria & 20.0 & 22.3 & 25.3 \\
Other Proteobacteria & 19.4 & 6.1 & 17.0 \\
Acidobacteria & 1.7 & 0.6 & 2.2 \\
Actinobacteria & 0.6 & $\mathrm{~N} / \mathrm{D}$ & $\mathrm{N} / \mathrm{D}$ \\
Bacteroidetes & 5.6 & 34.6 & 12.6 \\
Chloroflexi & 0.6 & $\mathrm{~N} / \mathrm{D}$ & $\mathrm{N} / \mathrm{D}$ \\
Deinococcus-Thermus & 5.0 & 1.7 & $\mathrm{~N} / \mathrm{D}$ \\
Planctomycetes & $\mathrm{N} / \mathrm{D}$ & 2.2 & $\mathrm{~N} / \mathrm{D}$ \\
Verrucomicrobia & 0.6 & 9.5 & $\mathrm{~N} / \mathrm{D}$ \\
Candidate phylum OP10 & 2.2 & 0.6 & $\mathrm{~N} / \mathrm{D}$ \\
Unknown Bacteria & 2.2 & 10.6 & 3.8 \\
\hline
\end{tabular}

a Betaproteobacteria are subdivided into Dechloromonas, Zoogloea, and other Betaproteobacteria.

${ }^{\mathrm{b}} \mathrm{N} / \mathrm{D}=$ not detected.

phyla Bacteroidetes and Verrucomicrobia increased. Within the Betaproteobacteria, the clones related to the genera Dechloromonas and Zoogloea decreased from $11.7 \%$ to $1.7 \%$ and from $30.6 \%$ to $10.1 \%$, respectively.

\section{Discussion}

4.1. Combined effects of oxygen chemisorption and direct sorption of perchlorate

Comparing the performances of the BAC and the glass bead reactors demonstrated that a sorptive carrier medium can enhance perchlorate removal substantially when reactors are exposed to increased DO concentrations. Under optimized operating conditions, the overall performance and the composition of the microbial community were similar in both reactors. Complete perchlorate and oxygen removal was achieved with acetate added as the electron donor in excess, 3.2 times the stoichiometric requirement. Different from the glass bead reactor, the BAC reactor maintained substantial perchlorate and oxygen removal rate during periods of increased influent DO concentrations when acetate addition was below the stoichiometric requirement (40-80\% of the requirement). This study dem- 
onstrated that sorption could support biological processes during dynamic reactor operations, such as increased influent DO concentrations and operation without electron donor addition-conditions that both resulted in substrate limitation for biological perchlorate removal.

Sorptive properties of GAC supported perchlorate removal most likely through a combination of oxygen chemisorption, which reduces bulk-phase DO concentrations and thus enhances biological perchlorate removal, and direct sorption of perchlorate. In the glass bead reactor, without any sorptive capacity, both the increase of influent DO concentrations and the operation without electron donor addition resulted in the complete breakthrough of perchlorate. The situation was different for the BAC reactor. Operation without electron donor addition resulted in increased effluent perchlorate concentrations up to $30 \mu \mathrm{g} / \mathrm{L}$ and no increase in effluent DO concentrations (Figure 4). These results demonstrate that sorption within the BAC, without biological perchlorate reduction, cannot remove perchlorate completely to below the detection limit. With baseline acetate addition and influent DO concentrations of $8 \mathrm{mg} / \mathrm{L}$, complete removal of both $\mathrm{DO}$ and perchlorate was achieved (Figure 1). The addition of a limited amount of electron donor ( $40 \%$ of the stoichiometric requirement) combined with oxygen removal through chemisorption resulted in sufficient biological perchlorate removal to achieve effluent concentrations below the detection limit in the BAC but not in the glass bead reactor.

Reduced bulk-phase DO concentrations in the BAC reactor alone, however, cannot explain the observed perchlorate removal. Bulk-phase DO concentrations on days 8 and 17 were approximately $0.1 \mathrm{mg} / \mathrm{L}$, but complete perchlorate removal was observed on day 17 , whereas the effluent perchlorate concentration on day 8 was approximately $10 \mu \mathrm{g} /$ L (Figure 1). The improved perchlorate removal on day 17 can be explained by the two backwash events on days 15 and 17, which likely resulted in an increased GAC surface area that was accessible not only for oxygen chemisorption but also for direct sorptive removal of perchlorate.

\subsection{Advantages and disadvantages of sorptive support medium for perchlorate removal}

In the literature there is no consensus on the benefits of sorptive support media and only limited information on the mechanisms of how biological perchlorate reduction can be supported by using sorptive biofilm support media is available. Sutton (2006) suggested that biological reduction should be supplemented with physico-chemical removal using for example GAC as a support medium. GAC could be beneficial both as a temporary sink and also to help increase local perchlorate concentrations on the GAC surface as the result of adsorption and desorption of perchlorate. This mechanism of temporary sorption to increase local perchlorate concentrations had been suggested by Herzberg et al. (2003). Other studies evaluating BAC reactors for perchlorate removal did not discuss possible effects of temporary sorption on reactor performance (Hatzinger, 2005; McCarty and Meyer, 2005). Kim and Logan (2000) went so far as to discourage the use of GAC due to nega- tive effects of desorption of perchlorate in a BAC reactor after backwashing. In their study, plug flow condition in the fixed bed reactor exposed BAC at the inlet of the reactor to high perchlorate concentrations. After backwashing and redistribution of filter media within the reactor, desorption of previously sorbed perchlorate close to the outlet of the reactor could not be reduced biologically and resulted in increased effluent perchlorate concentrations after backwashing. Thus, while plug flow conditions can be advantageous for biological processes due to higher substrate concentrations resulting in higher removal rates near the inlet of a reactor, these concentration gradients along the length of the reactor also have drawbacks. These drawbacks include the involuntary shuttling of sorbed perchlorate into the effluent, as described above, and heterogeneous biomass distributions. Choi and Silverstein (2007) have shown that completely mixed reactors (e.g., gas lift reactors or fixed bed reactors with recirculation) can provide a more even distribution of biomass and avoid the problem of increased effluent perchlorate concentrations after backwashing.

The discussion of sorption and desorption in this study was focused on macro-scale effects of the overall removal of perchlorate and oxygen from the bulk phase. This leads to interesting research questions to understand the influence of biofilm coverage, sorption, intraparticle diffusion, and mass transport within the GAC particle on the local availability of substrates for biological perchlorate removal (Herzberg et al., 2003). Another question that requires further research is the rate and extent of regeneration of the sorption capacity for both perchlorate and oxygen. Partial regeneration of oxygen chemisorption over a period of 2.5 days was observed in Figure 3. Long-term regeneration of sorption capacities over the course of reactor operation was demonstrated, as the sorption capacities of the GAC for oxygen and perchlorate had been exhausted before start-up and were regenerated over the course of reactor operation. The rate of regeneration of the sorption capacities was, however, not evaluated in this study.

\subsection{Critical bulk-phase oxygen concentrations for perchlorate removal}

This study demonstrated that chemisorption of oxygen resulted in reduced bulk-phase oxygen concentrations to sufficiently low levels so that biological perchlorate reduction could occur (approx. $0.05 \mathrm{mg}$ DO/L). McCarty and Meyer (2005) used a fluidized bed reactor for perchlorate removal from groundwater. They observed perchlorate removal within the first $25 \mathrm{~cm}$ of the reactor where bulk-phase DO concentrations were greater than $2 \mathrm{mg} / \mathrm{L}$ as long as sufficient electron donor was present. McCarty and Meyer (2005) explained this perchlorate reduction in the presence of relatively high bulk-phase DO concentrations based on mass transfer-limited anaerobic zones inside the biofilm. Complete overall perchlorate removal in their reactor was, however, associated with low effluent DO and nitrate concentrations of 0.1 and $0.01 \mathrm{mg} / \mathrm{L}$, respectively. The extent to which perchlorate removal can occur at elevated bulkphase DO concentrations depends on the biofilm structure (i.e, the biofilm needs to be sufficiently thick to allow for the 
development of anaerobic zones) and the electron donor to acceptor ratio in the bulk phase (Choi et al., 2007; McCarty and Meyer, 2005). In most reactor studies, information on biofilm structure is not reported. For fixed bed reactors, as in the current study, representative sampling of GAC with attached biofilm without disturbing the biofilm structure is usually difficult. This study focused on evaluating the feasibility of oxygen chemisorption on perchlorate removal. Further research needs to evaluate the influence of the type of reactor, reactor operation, and the resulting biofilm structure on the interactions between sorption/desorption on GAC surface and biological reduction processes.

\subsection{Microbial community structure}

Our study showed that Dechloromonas spp were the only known perchlorate-reducing bacteria in the two bioreactors, both of which used acetate as the sole electron donor. The importance of Dechloromonas spp. in perchlorate-reducing systems had also been suggested by Zhang et al. (2005), who evaluated the microbial community in an acetate-fed pilot-scale fixed bed bioreactor. In their study, based on the results from fluorescence in situ hybridization, Zhang and coworkers reported that Dechloromonas spp. accounted for about $23 \%$ and $1 \%$ of the bacterial populations at the surface and at the bottom of the biofilm, respectively. In comparison, based on clone library results, we reported the relative abundances of Dechloromonas as $11.7 \%$ and $13.2 \%$ in the $\mathrm{BAC}$ and the glass bead reactors, respectively. Zhang and coworkers also reported Dechlorosoma spp. to be present at low abundance in their system, while we did not detect any Dechlorosoma spp. in our systems (note that the Dechlorosoma genus has been renamed as Azospira; Dechlorosoma suillum (Achenbach et al., 2001) is a later subjective synonym of Azospira oryzae (Reinhold-Hurek and Hurek, 2000)). The relative abundances of perchlorate-reducing bacteria in the BAC and the glass bead reactors should not be considered low, because the influent perchlorate concentration was low compared to the influent DO level (i.e., 50 vs. $1000 \mu \mathrm{g} / \mathrm{L}$ ), and the microbial communities in the two reactors likely did not need to maintain large perchlorate-reducing bacterial populations to reduce the small amount of perchlorate. Finally, for the baseline operation condition, the levels of the most abundant bacterial populations were similar in the two reactors, while some less abundant bacterial populations were shown to be present in the BAC reactor only. We speculate that the roughness of the GAC surface provides a wider range of environmental niches than the glass surface, resulting in a more diverse microbial community in the GAC biofilm compared to the biofilm in the glass bead reactor.

The observation of similar major bacterial populations in the two reactors supported our conclusion that the differences in the response of both reactors to short-term exposure to increased DO levels (Figure 1 and Figure 2) were due to the sorptive nature of GAC rather than to differences in microbial composition. The change in the microbial community after long-term exposure to increased DO concentrations (Figure 3) demonstrated a direct influence of reactor operation on the competition of perchlorate-reducing bacteria with other heterotrophic bacteria.

\section{Conclusions}

This is the first report demonstrating that using a sorptive biofilm support medium can enhance biological perchlorate reduction through chemisorption of oxygen (the competing electron acceptor), in addition to the removal of perchlorate by direct sorption. Substantial removal of both oxygen and perchlorate was achieved for short periods (12 h) with influent DO concentrations of up to $8 \mathrm{mg} / \mathrm{L}$ in the BAC reactor. Using a non-sorptive support medium, complete breakthrough of perchlorate was observed for increased influent DO concentrations. During long-term exposure $(23 \mathrm{~d})$, the sorptive removal of DO and perchlorate slowly decreased. Application of sorptive support media is advantageous for biofilm reactors exposed to transient operating conditions, such as variable influent DO levels, reactor backwashing, and periods without electron donor addition. Partial regeneration of the sorption capacity was observed after long-term exposure to increased influent DO levels but mechanisms and kinetics of this regeneration should be further evaluated.

\section{Acknowledgments}

The authors would like to thank Vernon Snoeyink and Jess Brown for helpful discussions. This research was supported by the US National Science Foundation, Grant no. BES-0123342.

\section{References}

Abuzaid and Nakhla, 1994 N. S. Abuzaid and G. F. Nakhla, Dissolved-oxygen effects on equilibrium and kinetics of phenolics adsorption by activated carbon, Environ. Sci. Technol. 28 (2) (1994), pp. 216-221.

Achenbach et al., 2001 L. A. Achenbach, U. Michaelidou, R. A. Bruce, J. Fryman, and J. D. Coates, Dechloromonas agitata gen. nov., sp nov and Dechlorosoma suillum gen. nov., sp nov., two novel environmentally dominant (per)chlorate-reducing bacteria and their phylogenetic position, Int. J. Syst. Evol. Microbiol. 51 (2001), pp. 527-533.

APHA and WEF and AWWA, 1998 APHA, WEF and AWWA In: L. S. Clesceri, A. E. Greenberg and A. D. Eaton, Editors, Standard Methods for the Examination of Water and Wastewater (20th ed), American Public Health Association, Washington, DC (1998).

Brown et al., 2002 J. C. Brown, V. L. Snoeyink, and M. J. Kirisits, Abiotic and biotic perchlorate removal in an activated filter, J. Am. Water Works Assoc. 94 (2) (2002), pp. 70-79.

CADHS, 2004 CADHS, Conditional Acceptance of Fixed-Bed Biological Treatment for the Production of Drinking Water from Perchlorate-Contaminated Water, Letter from the California Department of Health Services to Carollo Engineers (2004).

Chen et al., 2005 W. F. Chen, F. S. Cannon, and J. R. RangelMendez, Ammonia-tailoring of GAC to enhance perchlorate removal. II: perchlorate adsorption, Carbon 43 (3) (2005), pp. 581-590.

Choi and Silverstein, $2007 \rightarrow$ H. Choi and J. Silverstein, Effluent recirculation to improve perchlorate reduction in a fixed biofilm reactor, Biotechnol. Bioeng. 98 (1) (2007), pp. 132-140. 
Choi et al., 2007 Y. C. Choi, X. Li, L. Raskin, and E. Morgenroth, Effect of backwashing on perchlorate removal in fixed bed biofilm reactors, Water Res. 41 (9) (2007), pp. 1949-1959.

Coates and Achenbach, 2004 J. D. Coates and L. A. Achenbach, Microbial perchlorate reduction: rocket-fuelled metabolism, Nat. Rev. Microbiol. 2 (7) (2004), pp. 569-580.

Coates et al., 1999 J. D. Coates, U. Michaelidou, R. A. Bruce, S. M. O'Connor, J. N. Crespi, and L. A. Achenbach, Ubiquity and diversity of dissimilatory (per)chlorate-reducing bacteria, Appl. Environ. Microbiol. 65 (12) (1999), pp. 5234-5241.

Cole et al., 2007 J. R. Cole, B. Chai, R. J. Farris, Q. Wang, A. S. Kulam-Syed-Mohideen, D. M. McGarrell, A. M. Bandela, E. Cardenas, G. M. Garrity, and J. M. Tiedje, The ribosomal database project (RDP-II): introducing myRDP space and quality controlled public data, Nucleic Acids Res. 35 (2007), pp. D169-D172.

Dojka et al., 1998 M. A. Dojka, P. Hugenholtz, S. K. Haack, and N. R. Pace, Microbial diversity in a hydrocarbon- and chlorinated-solvent-contaminated aquifer undergoing intrinsic bioremediation, Appl. Environ. Microbiol. 64 (10) (1998), pp. 3869-3877.

Gullick et al., $2001>$ R. Q. Gullick, M. W. Lechvallier, and T. A. S. Barhorst, Occurrence of perchlorate in drinking water sources, J. Am. Water Works Assoc. 93 (1) (2001), pp. 66-77.

Hanaki et al., 1997 K. Hanaki, T. Saito, and T. Matsuo, Anaerobic treatment utilizing the function of activated carbon, Water Sci. Technol. 35 (8) (1997), pp. 193-201.

Hatzinger, $2005>$ P. B. Hatzinger, Perchlorate biodegradation for water treatment, Environ. Sci. Technol. 39 (11) (2005), pp. 239A-247A.

Herzberg et al., $2003 \rightarrow$ M. Herzberg, C. G. Dosoretz, S. Tarre, and M. Green, Patchy biofilm coverage can explain the potential advantage of BGAC reactors, Environ. Sci. Technol. 37 (18) (2003), pp. 4274-4280.

Jaar and Wilderer, 1992 M. A. A. Jaar and P. A. Wilderer, Granular activated carbon sequencing batch biofilm reactor to treat problematic wastewaters, Water Sci. Technol. 26 (5-6) (1992), pp. 1195-1203.

Kim and Logan, $2000>$ K. Kim and B. E. Logan, Fixed-bed bioreactor treating perchlorate-contaminated waters, Environ. Eng. Sci. 17 (5) (2000), pp. 257-265.

Lin, 2004 Lin, R., 2004. Bacterial community analysis and optimization of biologically active carbon filters used to remove perchlorate from groundwater.

Losi et al., 2002 M. E. Losi, T. Giblin, V. Hosangadi, and J. Frankenberger, Bioremediation of perchlorate-contaminated groundwater using a packed bed biological reactor, Bioremediation J. 6 (2) (2002), p. 97.

Matos et al., 2006 C. T. Matos, S. Velizarov, J. G. Crespo, and M. A. M. Reis, Simultaneous removal of perchlorate and nitrate from drinking water using the ion exchange membrane bioreactor concept, Water Res. 40 (2) (2006), pp. 231-240.

McCarty and Meyer, 2005 P. L. McCarty and T. E. Meyer, Numerical model for biological fluidized-bed reactor treatment of perchlorate-contaminated groundwater, Environ. Sci. Technol. 39 (3) (2005), pp. 850-858.

Min et al., $2004 \longrightarrow$ B. Min, P. J. Evans, A. K. Chu, and B. E. Logan, Perchlorate removal in sand and plastic media bioreactors, Water Res. 38 (1) (2004), pp. 47-60.
Nerenberg and Rittmann, $2004>$ R. Nerenberg and B. E. Rittmann, Hydrogen-based, hollow-fiber membrane biofilm reactor for reduction of perchlorate and other oxidized contaminants, Water Sci. Technol. 49 (11-12) (2004), pp. 223-230.

Nerenberg et al., $2002 \checkmark$ R. Nerenberg, B. E. Rittmann, and I. Najm, Perchlorate reduction in a hydrogen-based membranebiofilm reactor, J. Am. Water Works Assoc. 94 (11) (2002), pp. 103-114.

Niquette et al., $1998>$ P. Niquette, M. Prevost, R. G. Maclean, D. Thibault, J. Coallier, R. Desjardins, and P. Lafrance, Backwashing first-stage sand-BAC filters, J. Am. Water Works Assoc. 90 (1) (1998), pp. 86-97.

Parette and Cannon, $2005-$ R. Parette and F. S. Cannon, The removal of perchlorate from groundwater by activated carbon tailored with cationic surfactants, Water Res. 39 (16) (2005), pp. 4020-4028.

Prober et al., $1975 \triangleright$ R. Prober, J. J. Pyena, and W. E. Kiddon, Interactions of activated carbon with dissolved oxygen, Aiche J. 21 (6) (1975), pp. 1200-1204.

Reinhold-Hurek and Hurek, $2000 \rightarrow$ B. Reinhold-Hurek and T. Hurek, Reassessment of the taxonomic structure of the diazotrophic genus Azoarcus sensu lato and description of three new genera and new species, Azovibrio restrictus gen. nov., sp nov., Azospira oryzae gen. nov., sp nov and Azonexus fungiphilus gen. nov., sp nov, Int. J. Syst. Evol. Microbiol. 50 (2000), pp. 649-659.

Richardson et al., 2002 R. E. Richardson, V. K. Bhupathiraju, D. L. Song, T. A. Goulet, and L. varez-Cohen, Phylogenetic characterization of microbial communities that reductively dechlorinate TCE based upon a combination of molecular techniques, Environ. Sci. Technol. 36 (12) (2002), pp. 2652-2662.

Rikken et al., 1996 G. B. Rikken, A. G. M. Kroon, and C. G. vanGinkel, Transformation of (per)chlorate into chloride by a newly isolated bacterium: reduction and dismutation, Appl. Microbiol. Biotechnol. 45 (3) (1996), pp. 420-426.

Roquebert et al., 2000 In: V. Roquebert, S. Booth, R. S. Cushing, G. Crozes, and E. Hansen, Editors, Electrodialysis reversal $(E D R)$ and ion exchange as polishing treatment for perchlorate treatment, Desalination 131 (1-3) (2000), pp. 285-291.

Sutton, 2006 P. M. Sutton, Bioreactor configurations for ex-situ treatment of perchlorate: a review, Water Environ. Res. 78 (13) (2006), pp. 2417-2427.

Urbansky, 1998 E. T. Urbansky, Perchlorate chemistry: implications for analysis and remediation, Bioremediation J. 2 (2) (1998), pp. 81-95.

USEPA, 1997 USEPA, Method 300. 1: Determination of Inorganic Anions in Water by Ion Chromatography, US EPA, Cincinnati, OH (1997).

Zhang et al., $2005 \rightarrow$ H. Zhang, B. E. Logan, J. M. Regan, L. A. Achenbach, and M. A. Bruns, Molecular assessment of inoculated and indigenous bacteria in biofilms from a pilot-scale perchlorate-reducing bioreactor, Microb. Ecol. 49 (3) (2005), pp. 388-398.

Zhu et al., $2000-$ X. Y. Zhu, S. M. Lee, Y. H. Lee, and T. Frauenheim, Adsorption and desorption of an O-2 molecule on carbon nanotubes, Phys. Rev. Lett. 85 (13) (2000), pp. 2757-2760. 